\title{
MICROSTRUCTURES AND MECHANICAL PROPERTIES OF TWO-PHASE ALLOYS BASED ON $\mathrm{NbCr}_{2}$
}

Katherine C. Chen, Paul G. Kotula*, Carl M. Cady, Michael E. Mauro, and Dan J. Thoma Los Alamos National Laboratory, Los Alamos, NM 87545, USA, kchen@lanl.gov

*Sandia National Laboratories, Albuquerque, NM 87185-1405

\section{ABSTRACT}

A two-phase, $\mathrm{Nb}-\mathrm{Cr}$ - $\mathrm{Ti}$ alloy (bcc $+C 15$ Laves phase) has been developed using several alloy design methodologies. In effort to understand processing-microstructure-property relationships, different processing routes were employed. The resulting microstructures and mechanical properties are discussed and compared. Plasma arc-melted samples served to establish baseline, as-cast properties. In addition, a novel processing technique, involving decomposition of a supersaturated and metastable precursor phase during hot isostatic pressing (HIP), was used to produce a refined, equilibrium two-phase microstructure. Quasi-static compression tests as a function of temperature were performed on both alloy types. Different deformation mechanisms were encountered based upon temperature and microstructure.

\section{INTRODUCTION}

Laves phases $\left(\mathrm{AB}_{2}\right)$ comprise the largest single class of intermetallics and have attractive properties for high-temperature structural applications [1,2]. However, these intermetallics have been long overlooked due to brittleness at ambient temperatures. Recent studies have shown potential for Laves phases, and alloy development schemes have been proposed to improve the toughness of these alloys $[3,4,5,6]$. The alloy composition in this study has been selected based upon three design methodologies.

Nonstoichiometry and alloying additions have been shown to improve the toughness of Laves phases [4]. In particular, alloying $\mathrm{NbCr}_{2}$ with $\mathrm{Ti}$ has been shown to improve the fracture toughness by indentation [7]. Thus, the $\mathrm{NbCr}_{2}$ phase field was extended out towards ternary space with additions of Ti. Another approach to improving the brittleness of Laves phase alloys is to incorporate an additional, more ductile phase. The Laves phase has been shown to deform when within a bec matrix [8], and two-phase Laves alloys appear to be the direction for practical applications. The alloy in this study was selected to be within the Nb-rich, solid solution bec + C15 phase field.

Lastly, various processing routes were used to explore the control of microstructures and properties. (Sentence removed) Previous studies on the crack growth and fracture modes showed severe cracking and fracture of the Laves phase networks along the bcc grain boundaries, and attested to the need for microstructural refinement [5]. In a departure from traditional arc-cast processing, an alloy of $10 \mathrm{Nb}-10 \mathrm{Ti}-80 \mathrm{Cr}$ had been melt-spun and annealed to demonstrate uniform phase distributions on a micron scale [9]. Thus, melt spinning of the current alloy composition was used to produce a similar metastable bcc precursor with relatively homogeneous 


\section{DISCLAIMER}

This report was prepared as an account of work sponsored by an agency of the United States Government. Neither the United States Government nor any agency thereof, nor any of their employees, make any warranty, express or implied, or assumes any legal liability or responsibility for the accuracy, completeness, or usefulness of any information, apparatus, product, or process disclosed, or represents that its use would not infringe privately owned rights. Reference herein to any specific commercial product, process, or service by trade name, trademark, manufacturer, or otherwise does not necessarily constitute or imply its endorsement, recommendation, or favoring by the United States Government or any agency thereof. The views and opinions of authors expressed herein do not necessarily state or reflect those of the United States Government or any agency thereof. 


\section{DISCLAIMER}

Portions of this document may be illegible in electronic image products. Images are produced from the best available original document. 
compositions. The intent was to use the metastable precursor phase to control the microstructural evolution, and thereby improve the mechanical properties of the dual phase alloy. EXPERIMENTAL PROCEDURES

An alloy of nominal composition, $37 \mathrm{Nb}-36 \mathrm{Cr}-27 \mathrm{Ti}$ (at\%), was processed by plasma arc melting (PAM). The elemental constituents of niobium (99.9\%), chromium (99.99\%), and titanium (99.99\%) were melted into a 4" diameter water-cooled copper hearth. The alloy had a mass of about 3 kilograms, and was remelted four times. Chemical analysis by inert-gas fusion revealed impurity levels of $0.08 \mathrm{wt} \%$ oxygen and $0.06 \mathrm{wt} \%$ nitrogen.

The same alloy composition was prepared by arc-casting for the melt-spin process. Pieces were then loaded into a BN crucible. The melt-spinning chamber was evacuated to $<1.3$ $\mathrm{Pa}$ and back-filled with ultra-high purity helium three times. The operating pressure in the chamber was $\sim 8.4 \times 10^{4} \mathrm{~Pa}$. Using induction heating, the alloy was heated (within five minutes) to the pour temperature of $1800^{\circ} \mathrm{C}$. A helium gas pressure of $20.7 \times 10^{3} \mathrm{~Pa}$ ejected the molten alloy through the orifice onto the spinning copper. wheel to form ribbons. Partial reaction of the crucible resulted in boron additions in the alloy. The melt-spun ribbons were chopped into smaller pieces by a blender and pressed into a Ta can. The hot isostatic pressing (HIP) procedure involved initially pressurizing the chamber to $7 \mathrm{ksi}(50 \mathrm{MPa})$. Based upon the alloy decomposition signatures from differential thermal analyses (DTA), the material was ramped up to $1300^{\circ} \mathrm{C}$ in 90 minutes, held for an hour at pressures of about $30 \mathrm{ksi}(200 \mathrm{MPa})$, and then furnace cooled.

The alloys were characterized by optical microscopy, scanning electron microscopy (SEM), transmission electron microscopy (TEM), and x-ray diffraction (XRD). Compositions were analyzed by electron microprobe, energy dispersive spectroscopy (EDS), and atom location by channeling enhanced microanalysis (ALCHEMI). Quasi-static compression tests were conducted on cylindrical samples $(5 \mathrm{~mm} \times 5 \mathrm{~mm}$ ), and at least two samples were used for each temperature tested. Tests within the temperature range of $25^{\circ} \mathrm{C}-600^{\circ} \mathrm{C}$ were performed in air, while tests at the higher temperatures were done in vacuum. A strain rate of $0.001 / \mathrm{sec}$ was used.

\section{RESULTS AND DISCUSSION Microstructures}

The arc-melted alloy retained a metastable microstructure of supersaturated bcc phase and roughly 25 vol\% Laves phase. The Laves phase formed an almost continuous network of small particles $(<10 \mu \mathrm{m})$ along the grain boundaries of the bcc phase $(\sim 100 \mu \mathrm{m})$, as shown in Figure 1 . A Cr-depleted zone was found near the Laves phases along the grain boundaries, while the rest of the $\mathrm{Nb}$-rich bec grain was fairly uniform in composition. Upon testing at elevated temperatures $\left(>900^{\circ} \mathrm{C}\right)$, precipitation of the Laves phase occurred within the bce grains.

The melt-spun alloy experienced extremely fast cooling rates, and was an attempt to use metastable solidification pathways to create a compositionally homogeneous bcc solid solution [9]. A cross-sectional view of the melt-spun ribbon is shown in Figure 2, and depicts the finescale of the microstructure. The ribbons have a thickness of about $50 \mu \mathrm{m}$, and display submicron dendritic structure on the "air side" of the ribbon. The "chill side" of the ribbon is almost entirely 
metastable bcc. The lattice constants of the bcc phase give some indication of the degree of supersaturation (Table $\mathrm{I}$ ). Since the $\mathrm{Cr}$ atom is the smallest of the ternary elements, $\mathrm{Cr}$ supersaturated in the bec phase (as opposed to forming the more complicated (Nb, $\mathrm{Ti}) \mathrm{Cr}_{2}$ Laves phase) results in a smaller bcc lattice constant. Upon annealing treatments or testing at elevated temperatures, more Laves phase is formed, and the bce lattice constant increases. Microprobe, EDS, and ALCHEMI work confirm the analysis [5].

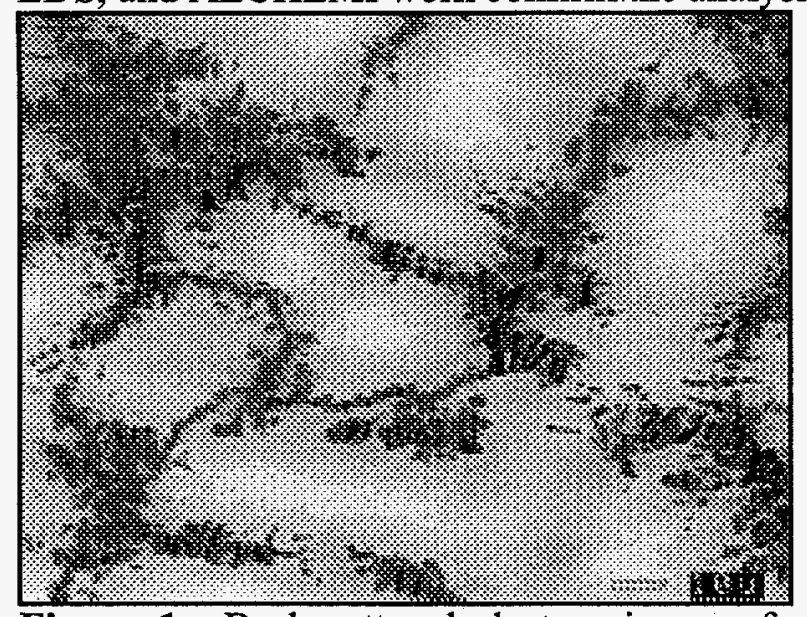

Figure 1. Backscattered electron image of the as-cast alloy shows the Laves phase (dark contrast) along the bcc grain boundaries. The alloy has been compressed at room temperature and displays microcracks within the Laves particles in the direction of compression.
Table I. Lattice constants of the bcc phase in different processing stages of the alloy.

\begin{tabular}{|l|l|}
\hline Sample & $\begin{array}{l}\text { bcc lattice } \\
\text { constant }(\AA)\end{array}$ \\
\hline $\begin{array}{l}\text { metastable* } \\
(37 \mathrm{Nb}-27 \mathrm{Ti}-36 \mathrm{Cr})\end{array}$ & 3.155 \\
\hline \hline $\begin{array}{c}\text { plasma arc-melted, } \\
\text { as-cast }\end{array}$ & $3.2203 \pm 0.0006$ \\
\hline $\begin{array}{c}\text { plasma arc-melted, } \\
1200^{\circ} \mathrm{C}\end{array}$ & $3.2714 \pm 0.0007$ \\
\hline $\begin{array}{c}\text { melt-spun ribbon, } \\
\text { chill side }\end{array}$ & $3.159 \pm 0.002$ \\
\hline $\begin{array}{c}\text { melt-spun ribbon, } \\
\text { air side }\end{array}$ & $3.200 \pm 0.005$ \\
\hline consolidated ribbon (HIP) & $3.266 \pm 0.001$ \\
\hline \hline $\begin{array}{c}\text { equilibrium* } \\
(-48 \mathrm{Nb}-43 \mathrm{Ti}-9 \mathrm{Cr})\end{array}$ & 3.269 \\
\hline
\end{tabular}

* calculated

After the HIP treatment, the consolidated ribbons show a very uniform distribution of the bcc and $C 15$ phases (Figure 3). The alloy has the equilibrium phases, as determined from XRD results. With this particular processing route, the $C 15$ Laves phase appears as small, equiaxed particles $(\sim 1 \mu \mathrm{m})$ and makes up $40 \mathrm{vol} \%$ of the alloy. The alloy has no obvious porosity, and resisted coarsening at the high test temperatures of $1200^{\circ} \mathrm{C}$. Thus this microstructure is believed to be quite stable. Small amounts of another phase, probably Ti-rich borides or bcc particles, are present and may be due to the melt-spinning operation or the solidification sequence.

\section{Mechanical Properties}

Compression tests of the PAM alloy at room temperature resulted in a yield stress of $1620 \mathrm{MPa}$ and ultimate stress of $1800 \mathrm{MPa}$. Much of the strength of the alloy can be attributed to the supersaturated bcc solid solution. Plastic strains were also measured to $16 \%$. After yielding, the stress displayed a plateau, indicating very little work hardening or a microstructural instability. Similar stress-strain behavior was exhibited by the as-cast alloys at $300^{\circ} \mathrm{C}$ and $600^{\circ} \mathrm{C}$. However, as the temperature increased, the yield stresses and the strains to failure decreased. Optical microscopy, SEM, and TEM examination of the compressed, as-cast alloys reveal cracking confined within the Laves phase. The bcc phase appears to blunt the cracks and provide the toughness to the system. Several microcracks in the direction of compression can be seen in the Laves particles in Figure 1. Large cracks traversing along the Laves network were also found and most likely cause the macroscopic failure of the test specimens. 
The as-cast alloys experience a drop in the plastic strain after $600^{\circ} \mathrm{C}$, most likely due to the microstructural instability at the higher temperatures. New Laves phases are evident after testing at $900^{\circ} \mathrm{C}$. By $1200^{\circ} \mathrm{C}$, most of the Laves phase has precipitated from the metastable bcc solid solution as submicron particles [5]. Microcracking within the large Laves particles is still persistent until $1200^{\circ} \mathrm{C}$, where the yield stress drops to $160 \mathrm{MPa}$. Extensive deformation takes place at this high temperature, and testing was stopped at a predetermined strain rather than continuing until fracture. Dislocations have been documented in $\mathrm{NbCr}_{2}$ at $1250^{\circ} \mathrm{C}$ [10], and

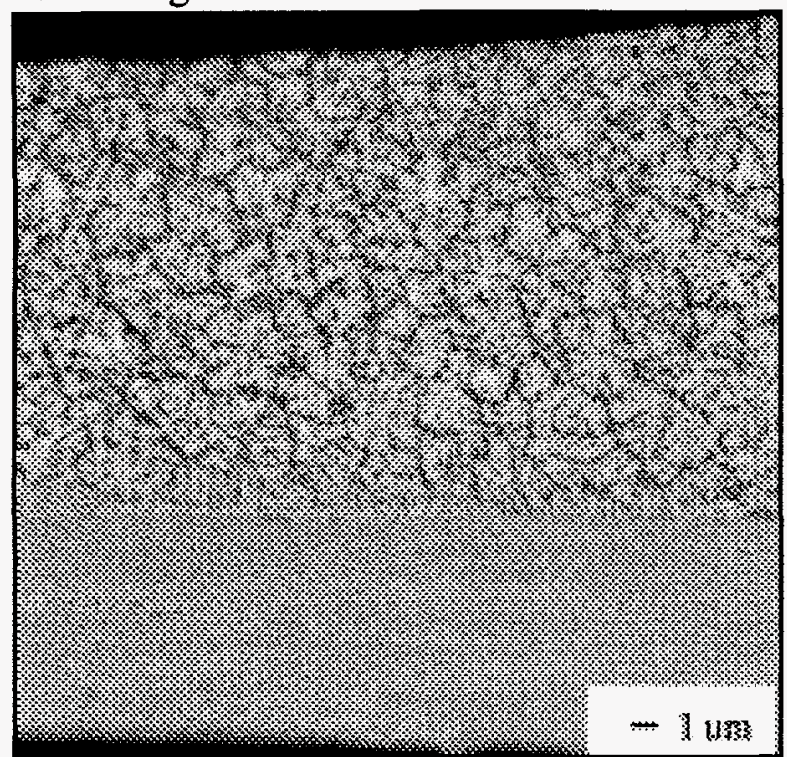

Figure 2. Cross-sectional view of the meltspun ribbon. The top portion or "air side" consists of a dendritic, bcc+C15 structure, while the bottom portion or "chill side" is mainly metastable bcc.

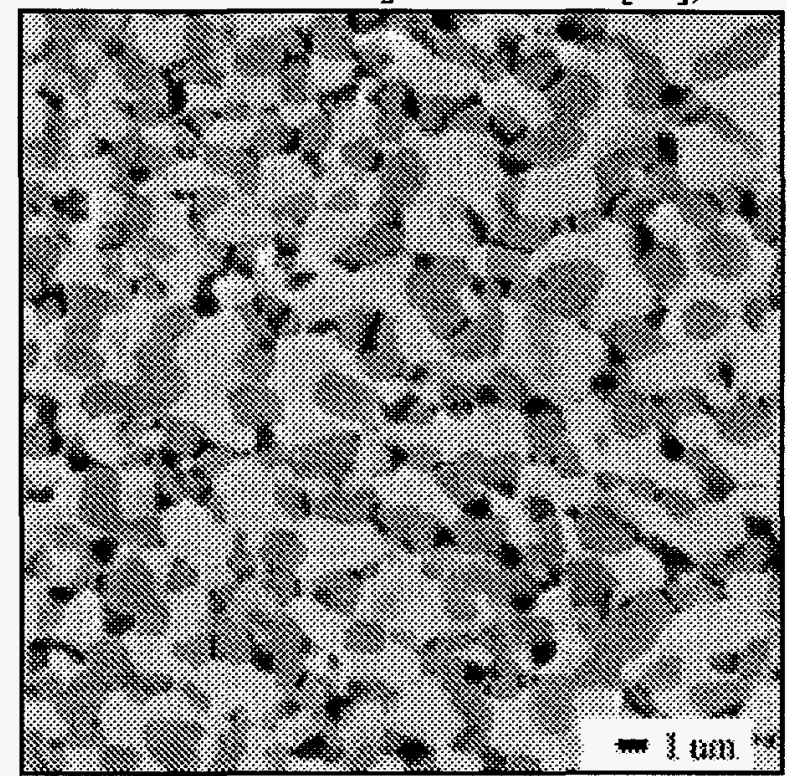

Figure 3. Backscattered electron image of the refined microstructure of the HIP alloy. Cracks along the interfaces of the Laves phase particles are due to compression at $900^{\circ} \mathrm{C}$.

deformation of the Laves phase is believed to occur at high temperatures $\left(\sim^{2} / T_{m}\right)$. The ductile to brittle transition temperature (DBTT) is estimated to be around $900^{\circ} \mathrm{C}$ for the as-cast material.

The HIP material had much higher strengths, with a yield stress of about $1680 \mathrm{MPa}$ and ultimate stress of $2350 \mathrm{MPa}$ at room temperature. However, less than $2 \%$ plastic strain could be withstood before the test specimens shattered into several pieces. The HIP alloy contains a much greater volume fraction of the Laves phase (40\%) than the as-cast alloy (25\%), and Laves phase particles have been shown to be effective strengtheners in other alloy systems [11]. Tests at the higher temperatures of $300^{\circ} \mathrm{C}, 600^{\circ} \mathrm{C}$, and $800^{\circ} \mathrm{C}$ also showed a decrease in yield stress, and little plasticity was experienced. No visible deformation or microcracking in the Laves phase was seen in these samples.

Microcracks began to appear in the HIP alloys after compression at the higher temperatures. However, these cracks are along the interface of the Laves phase particles (and especially along neighboring Laves particles), rather than within the particles (Figure 3 ). The DBTT of the HIP alloy occurs around $850^{\circ} \mathrm{C}$. At $900^{\circ} \mathrm{C}$, the HIP alloy exhibits much greater plastic strains, although the strength begins to be less than that of the as-cast material. Precipitation during high-temperature testing of the as-cast alloy resulted in a microstructural length scale less than that of the HIP alloy, thereby producing slightly higher strengths. No cracks are observed in the HIP sample compressed at $1200^{\circ} \mathrm{C}$. 
Figure 4 shows a summary of the compression tests as a function of test temperature. The differences in compression behavior are attributed to differences in the microstructures of the alloy. Different deformation mechanisms must also be operating in each alloy at particular temperature regimes. The convergence of mechanical properties of the two alloys at $1200^{\circ} \mathrm{C}$ coincides with the similitude in microstructures at that temperature.

Prior investigators of two-phase Laves systems [12] have proposed that at around room temperatures, Laves phases deform by twinning and thus appreciable amounts of deformation are possible. At the mid-temperature ranges, plastic strains are greatly reduced, as in the as-cast alloy. In this regime, the twinning deformation mechanism is no longer operative and slip has yet

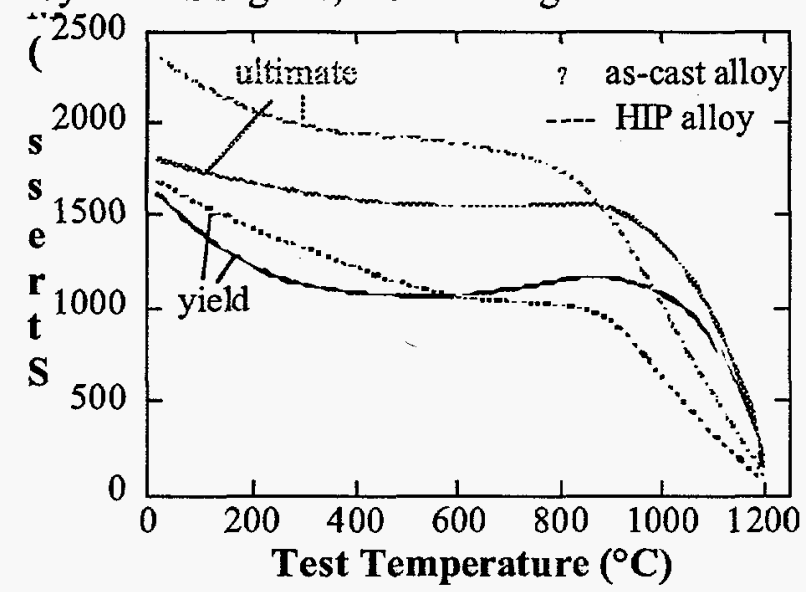

(a)

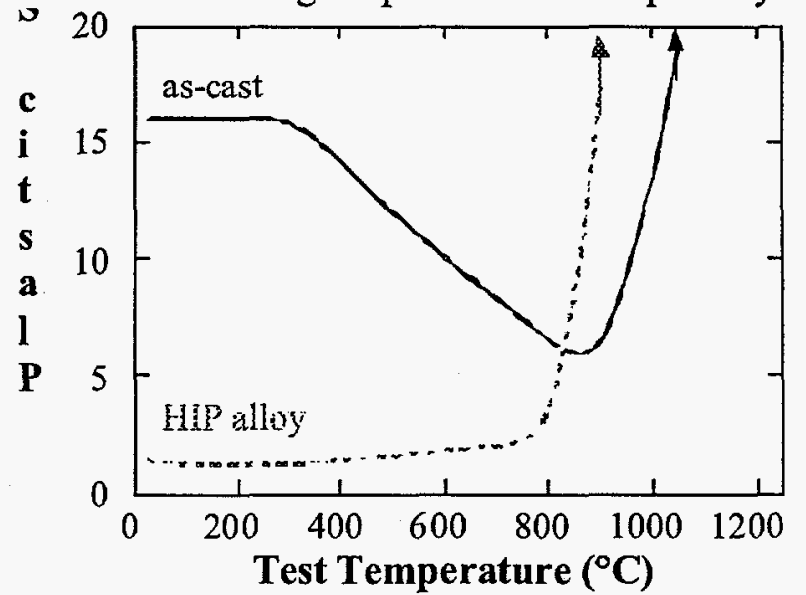

(b)

Figure 4. (a) Yield and ultimate stress, and (b) plastic strain as a function of compression test temperature of the as-cast (bold lines) and the HIP alloy (dashed lines).

to become available. However, the HIP alloy (with somewhat isolated Laves particles for favorable deformation conditions), exhibits quite low plasticity from room temperature to $900^{\circ} \mathrm{C}$. Either current interpretations are not applicable, or other factors may be dominating the behavior. The lack of microcracking in the HIP alloy is somewhat unexpected, considering the occurrence of cracking in several other Laves alloy systems [11]. The very small size of the Laves particles may somehow preclude cracking. The dislocation movement in the bcc phase may also be limited or constrained due to the small-sized grains [13]. While the bcc phase is the major constituent of the alloy, a continuous matrix may not truly exist and extensive flow or deformation may be hindered. (What about the boron..could that be a potential problem?)

Also noteworthy is that no gross deformation in the shape of the equiaxed grains is observed after more than $20 \%$ plastic strain. Similarly, an equiaxed and fine-grained $(\sim 1 \mu \mathrm{m})$ Cr-rich bcc $+\mathrm{NbCr}_{2}$ alloy (processed by ball milling and HIP) did not show any significant changes in microstructure after compression [14]. The large deformations may be due to grain boundary sliding, as with fine-grained materials that exhibit superplasticity. However, more work is needed to determine if such a mechanism is occurring. 
Macroscopic cracks in the HIP alloy were found to pursue a tortuous path that eventually followed along the Laves particle interfaces. In contrast, fairly straight crack propagation through the large bec grains was observed in the as-cast alloys in previous studies [5]. Brittle cleavage fracture of the bec phase was also evident in the as-cast material [5]. Intergranular fracture is experienced by the HIP alloys (Figure 5), and is consistent with the microcracking along the interfaces during compression. Fracture is energetically more favorable along the interface, rather than through the Laves particles in the HIP alloy. Thus, the small-scaled, two-phase microstructure of the HIP alloy influences the crack propagation and fracture mode, as well as

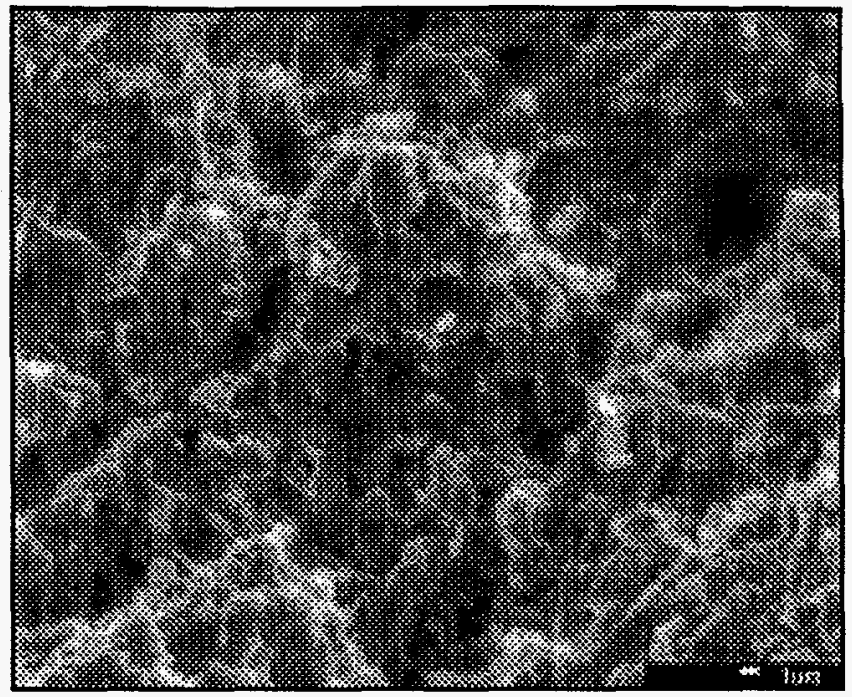
deformation.

\section{CONCLUSIONS}

In efforts to tailor mechanical properties, manipulations of the microstructure of a dual-phase $\mathrm{NbCrTi}$ alloy have been demonstrated.

1. The as-cast, plasma-arc-melted alloys have a metastable microstructure of supersaturated bcc phase and the $C 15$ Laves phase along the grain boundaries. At elevated temperatures, the Laves phase precipitates within the bcc grains.

2. Melt-spun ribbons of metastable bec precursor were consolidated through a HIP process. A fine-grained $(\sim 1 \mu \mathrm{m})$ microstructure consisting of the two equilibrium phases resulted, and was resistant to coarsening at test temperatures.

3. Room temperature yield and ultimate stresses for the as-cast alloy were 1620 and $1800 \mathrm{MPa}$, respectively, and for the HIP alloy were, 1680 and $2350 \mathrm{MPa}$. The as-cast alloys had plastic strains to $16 \%$, while the HIP alloy demonstrated less than $2 \%$.

4. Microstructural differences between the alloys caused different fracture modes and deformation mechanisms. Microcracking within the Laves phase was observed for the as-cast alloy, while interface cracking occurred in the HIP alloy. Intergranular fracture was also found with the HIP alloys.

5. Significant plasticity was afforded by both alloys at $1200^{\circ} \mathrm{C}$ compression with strengths greater than $70 \mathrm{MPa}$. No cracking occurred, and dislocations are found in the Laves phase.

\section{ACKNOWLEDGMENTS}

This research has been supported by DOE-OBES, Division of Materials Science. Sandia is a multiprogram laboratory operated by Sandia Corporation, a Lockheed Martin Company, for the United States Department of Energy under contract DE-AC04-94AL85000.

\section{REFERENCES}


1. R.L. Fleischer, Mater. Res. Soc. Symp. Proc. 133, 305 (1989).

2. D.L. Anton and D.M. Shah, Mater. Res. Soc. Symp. Proc. 213, 733 (1991).

3. J.D. Livingston, Phys. Stat. Sol. (a) 131, 415 (1992).

4. K.C. Chen, S.M. Allen, and J.D. Livingston, Mater. Sci. and Eng. A242, 163 (1998).

5. K.C. Chen, D.J. Thoma, P.G. Kotula, F. Chu, C. Cady, G.T. Gray III, P.S. Dunn, D.R. Korzekwa, C. Mercer, and W. Soboyejo, The Third Pacific Rim International Conference on Advanced Materials and Processing (PRICM 3), (TMS, 1998), p. 1431.

6. D.J. Thoma, F. Chu, P. Peralta, P.G. Kotula, K.C. Chen, and T.E. Mitchell, Mater. Sci. and Eng. A240, 251 (1997).

7. D.J. Thoma, $\mathrm{PhD}$ thesis, University of Wisconsin, 1992.

8. J.D. Livingston and E.L. Hall, J. Mater. Res. 5, 5 (1990).

9. K.C. Chen, P.G. Kotula, F. Chu, and D.J. Thoma, Mater. Res. Soc. Symp. Proc. 481, 89 (1998).

10. T. Takasugi, S. Hanada, M. Yoshida, Mat. Sci. Eng. A192/193, 805 (1995).

11. K.C. Chen, S.M. Allen, and J.D. Livingston, Mater. Res. Soc. Symp. Proc. 288, 373 (1993).

12. F. Chu and D.P. Pope, Mater. Res.. Soc. Symp. Proc. 288, 561 (1993).

13. K.S. Chan, D.L. Davidson, and D.L. Anton, Metall. Trans. 28A, 1797 (1997).

14. N. Aoyama and S. Hanada, Mat. Trans., JM 38, 155 (1997). 